TESTA, Enrico. Heróis e figurantes: o personagem no romance. Tradução de Patricia Peterle. São Paulo/Florianópolis: Rafael Copetti Editor, 2019, 183p.

\title{
Isolamento e porosidade do personagem em Heróis e figurantes, de Enrico Testa
}

\author{
Pedro Barbosa Rudge Furtado*
}

Destacam-se, entre os estudos que lidam com a categoria narrativa do personagem, ${ }^{1}$ dois textos basilares: o canônico ensaio "A personagem do romance", de Antonio Candido (2007), contido em A personagem de ficção, e o profundo e extenso trabalho de Michel Zéraffa (2010) em Pessoa e personagem: o romanesco dos anos de 1920 aos anos de 1950.

Ambos investigam, de modo mais ou menos pormenorizado, o que o intelectual brasileiro denomina a passagem paulatina, iniciada no romance moderno do século XVIII, do "enredo complicado com personagem simples, para o enredo simples (coerente, uno) com personagem complicada", em que Ulysses, de James Joyce, figura o ápice da complicação do ser-de-papel. De acordo com Zéraffa (2010, p. 19), tal mudança de representação dessa categoria narrativa está intrinsecamente atada ao modo como a pessoa se vê. Se ela se enxerga fracionada, dividida, em decomposição psicológica, a linguagem do romance altera-se a fim de conseguir representar com mais exatidão os movimentos psíquicos do personagem em tensão consigo e com o exterior.

\footnotetext{
* Doutorando pelo Programa de Pós-Graduação em Estudos Literários da Faculdade de Ciências e Letras de Araraquara (UNESP); mestre pelo mesmo programa (2017); professor substituto de "Críticas Literárias" no curso de Letras da UNESP de Araraquara (2019 e 2020). Bolsista CAPES. ORCID: http://orcid. org/0000-0002-4786-0716.

1 Enrico Testa usa "personagem" como substantivo masculino. Como a sua obra é a resenhada, preferimos adotar, também, essa atitude gramatical. Antonio Candido, por outro lado, prefere fazer uso dessa palavra como substantivo feminino. Mantemos as citações tais como elas estão grafadas nos livros citados.
} 
Esse veio de investigação do eu em consonância com a figuração mental do ser-de-papel também é encontrado no cerne do livro Heróis e figurantes: o personagem no romance, do poeta e professor italiano Enrico Testa (2019). Diferentemente das duas obras anteriormente mencionadas, a de Testa traz reflexões, acerca da categoria narrativa destacada, na literatura, senão contemporânea - a depender da dimensão temporal e formal abraçada por cada pesquisador no intuito de definir os parâmetros do que é literatura contemporânea - mais próxima aos nossos dias atuais, compreendendo prosas do anos de 1980 e 1990, como de Paul Auster, Ian McEwean, Javier Marías entre outros. Somada à observação desses autores, há a de literatos considerados clássicos do século XIX e, especialmente, do século XX. A fim de assinalarmos o alcance de suas propostas, pensamos, de modo sucinto, como algumas narrativas da literatura brasileira podem estar inseridas nas modulações conceituais do intelectual.

A grande abrangência temporal dos estudos de Testa não motiva uma análise rasa do tema proposto nos romances selecionados. Muito pelo contrário, a sua erudição, em amalgama com a precisão crítica de seus escritos, engendra ensaios mais ou menos claros - a depender da densidade dos assuntos tratados - em que o autor apresenta uma intensa noção formal da malha literária ao mesmo tempo em que coloca em jogo questões filosóficas e sociais irradiadas pelas narrativas.

Dessa forma, é concebida uma obra que, mesmo às vezes fragmentariamente, historiciza a ideia de personagem com o fito de constatar o desenvolvimento dessa categoria da narrativa no que está relacionado à sua porosidade, sobretudo diante da 
confluência de perspectivas encerradas na diegese. Para isso, o intelectual italiano constrói conceitos relativamente firmes acerca do personagem enquadrado na narração. As duas concepçõesbase do livro, que originam outras, são a de "personagem absoluto" e "personagem relativo".

Os três primeiros capítulos investigam a proliferação do personagem absoluto como fruto e repercussão, a posteriori, do niilismo existencialista em maior ou menor grau. Lidando com romances de Kafka, Beckett e Bernhard, Testa aponta para a quase imanência do sentido de negatividade - melancolia, nostalgia, mal-estar em geral -, com o personagem sendo a sua força-motriz, figurado dialeticamente na forma e no conteúdo dessas obras.

No autor d'O castelo há uma cesura radical com a realidade exterior, vazada em gestos soberanos do narrador, que "impõe a região mental do protagonista, seu espaço interior”, sem identidade formada e "com um cambiante caleidoscópio de imagens" (TESTA, 2019, p. 22) como o núcleo diegético. Em Beckett o eu ainda é central, apesar de diluir-se na própria forma amorfa de suas narrativas, que invocam o niilismo do ser: "a imobilidade e a ausência de evolução, o cansaço e o sentido de não pertencimento, a tendência à anomia, a falta de relações, o sentimento paranoico e persecutório" (TESTA, 2019, p. 33) provocando fatalmente o afeto do desamparo da solidão. Já no caso dos seres-de-papel de Bernhard, o insulamento do eu é elaborado pelo aviltamento do outro; isto é, "tudo é apresentado na roupagem do inimigo e toda relação é fundada na ligação do 'horror' " (TESTA, 2019, p. 38).

Como notamos, todas as personagens arroladas nas prosas dos três primeiros ensaios são, de acordo com o poeta crítico, personagens absolutas, caracterizadas pela ausência de 
transformação, "por uma passional aspiração do verdadeiro em detrimento de qualquer outros valor; e por uma exasperação da subjetividade, que tem, no plano compositivo, devido a seu objetivo extremo, a forma do monólogo". A falta de porosidade, por fim, coloca-a numa posição trágica de "dissídio com a realidade" (TESTA, 2019, p. 145).

$\mathrm{Na}$ literatura brasileira essa personagem ganha corpo nos nossos romances intimistas, especialmente em primeira pessoa: Bento Santiago, em Dom casmurro (1889), ${ }^{2}$ detém propriedades, a voz narrativa e Capitu; Luís da Silva, em Angústia (1937), projeta a sua derrocada social no outro em constante antagonismo com o eu; Belmiro, n'Amanuense Belmiro (1937), apresenta o afã de afastar-se do presente por meio da escrita de um diário memorialístico. Em comum, elas são as únicas a ter perspectivas sobre os fatos narrados, deturpando a realidade mediante a influência da fantasmagoria que as perturba, não o suficiente, no entanto, para modificar a sua cosmovisão.

Em contraposição aos seres-de-papel absolutistas, há os personagens relativos, tratados no quarto ensaio do livro. Nelas, a psicologia individual não interdita o embate permeável com a cosmovisão do outro. Diversamente dos absolutistas, nos relativos existe uma certa negociação com o exterior, forjando a evolução do ser que necessita do mundo, que com ele se envolve mesmo em conflito. Testa (2019) afirma que esse tipo de romance tem como lastro as narrativas dos séculos anteriores, em que o enredo rico de peripécias encetava mudanças comportamentais dos atores da prosa, apesar de elas serem algumas vezes quase imperceptíveis. Esses personagens estão inseridos em três variedades de narrativas: a dual, a da sombra e a policêntrica.

2 São indicados os anos da primeira publicação das obras. 
Na dual há, normalmente, duas figuras rivais em choque que delineiam uma relação ética com o mundo a partir da aderência, do narrador ou do leitor, a uma das cosmovisões representadas. A bivocalidade faz surgir uma terceira voz, que propõe mediar o embate, evitando os "trágicos efeitos" (TESTA, 2019, p. 74) da implosão de subjetividades. No complexo Calunga (1935), de Jorge de Lima, por exemplo, a narrativa encaixa-se na dualidade até certo ponto. Lula, o civilizador da ilha de Santa Luzia, aos poucos é derrotado na sua empreitada, tornando-se Totô Canindé, seu adversário, representante do modus vivendi bárbaro e atrasado do local. Assim, não há uma voz - nem uma perspectiva - extra que harmonize o fracasso sobretudo de Lula.

Diferentemente da dual, a narração sombra estabelece um vínculo da personagem principal com alguém morto. Ela está atrelada, então, com o constante movimento de lamentação e, talvez, confissão de culpa do ser-de-papel envolvido num torneio dialético de ausência/presença do outro: ausência física, presença psicológica. Narrativas do luto ou da melancolia, as chamaríamos. São Bernardo (1935) talvez seja o romance paradigmático dessa classe composicional na nossa literatura. Por mais que Paulo Honório não afirme categoricamente, o seu relato é construído e motivado pela esposa morta. Mesmo nos momentos de maior objetividade da prosa, a coruja pia, ecoando as lembranças sobre Madalena.

Se as variedades anteriores das personagens relativas ligavam-se à dependência de dois atores narrativos, no tipo policêntrico a narração é estruturada por meio de diversas vozes, não havendo protagonistas. Elabora-se uma intensa carga teatral no relato que é conduzido, no seu cerne, através do diálogo entre os personagens, uma vez que desaparece o "papel 
onisciente do narrador" (TESTA, 2019, p. 100). A edificação da história plurivocal nos remete diretamente às ideias de romance polifônico de Mikhail Bakhtin, como vemos a seguir: "os muitos 'focos' do discurso narrativo não só se opõem um ao outro, mas parecem - no cruzamento das diferentes perspectivas das quais são portadores - se fecundarem (ou se negarem) reciprocamente" (TESTA, 2019, p. 100).

Entretanto, Enrico Testa não cita o estudioso russo em tal capítulo, sendo que até o seu vocabulário é similar ao bakhtiniano. Há diferenças óbvias entre as definições de ume de outro. Segundo Bakhtin (2013, p. 64), a palavra do narrador também está inserida na polifonia combativa do romance, "plenivalente e totalmente genuína" sua e dos personagens. Assim, o narrador é vital na distribuição de perspectivas, emprestando aos heróis, muitas vezes, a voz por meio do discurso indireto-livre, não tão somente mediante diálogos. Mesmo diante da noção de amortecimento da importância do narrador - além da despreocupação do intelectual italiano com a pulverização de miradas sociais, o que é altamente relevante para o marxista Bakhtin - acreditamos que o linguista russo deveria ter sido mencionado, pois apresenta-se como fonte clara do desdobramento da definição de Testa.

De qualquer maneira, a concepção de narrativas atomizadas em termos de foco narrativo é bastante interessante, porém é aparentemente a mais rara entre os tipos conceituados. Desde de Crônica da casa assassinada (1959), de Lúcio Cardoso, até Sinuca embaixo d'água (2009), de Carol Bensimon e As margens do paraíso (2019), de Lima Trindade - romances totalmente diferentes no tocante aos assuntos representados e ao momento de publicação - normalmente a perspectiva narrativa é passada de um personagem a outro, edificando, então, o mosaico 
de miradas. O dialogismo dá-se por meio de blocos narrativos de capítulos, trechos, segmentos etc - em que um ser-de-papel vê, não mediante à cena teatral.

Entretanto, toda definição é apenas relativamente estável, servindo, normalmente, como ponto de partida da percepção de que o texto literário a desafia de forma constante. Assim, a conceitualização, demasiado relevante na teoria-crítica literária, cria uma base consistente de associação e desassociação das narrativas aos seus preceitos, como percebemos, bastante brevemente, em algumas prosas brasileiras relacionadas às proposições, sempre abertas a discussão, do livro resenhado.

No fim e ao cabo, muito em virtude das proposta de leitura do personagem, nunca desprendida das outras categorias da narrativa, a obra de Testa entra no rol de pertinentes estudos acerca dos seres-de-papel, especialmente por meio da edificação do inflexível e complexo personagem absoluto - fechado normalmente numa psicologia doente do eu - difundido no século $\mathrm{XX}$ - e do personagem relativo - poroso, mesmo que minimamente, ao diálogo com o outro e com o mundo - provindo, sobretudo em termos formais, do início do romance moderno em que o desenrolar das ações são fundamentais no desenrolar do personagem.

\section{Referências}

BAKHTIN, Mikhail. Problemas da poética de Dostoiévski. Tradução de Paulo Bezerra. 5. ed. Rio de Janeiro: Forense Universitária, 2013.

CANDIDO, Antonio. A personagem do romance. In: CANDIDO, Antonio. A personagem de ficção. São Paulo: Perspectiva, 
2007. p. 51-80.

TESTA, Enrico. Heróis e figurantes: o personagem no romance. Tradução de Patricia Peterle. São Paulo/Florianópolis: Rafael Copetti Editor, 2019.

ZÉRAFFA, M. Pessoa e personagem: o romanesco dos anos de 1920 aos anos de 1950.

Tradução de Luiz João Gaia e J. Guinsburg. São Paulo: Perspectiva, 2010. 